\title{
Zeb1 Is a Potential Regulator of Six2 in the Proliferation, Apoptosis and Migration of Metanephric Mesenchyme Cells
}

\author{
Yuping Gu ${ }^{1,+}$, Ya Zhao ${ }^{1,2,+}$, Yuru Zhou ${ }^{1,3,+}$, Yajun Xie ${ }^{1}$, Pan Ju ${ }^{1}$, Yaoshui Long ${ }^{1}$, Jianing Liu ${ }^{1}$, \\ Dongsheng Ni ${ }^{1}$, Fen Cao ${ }^{1}$, Zhongshi Lyu ${ }^{1}$, Zhaomin Mao ${ }^{1}$, Jin Hao ${ }^{1}$, Yiman Li ${ }^{1}$, Qianya Wan ${ }^{1}$, \\ Quist Kanyomse ${ }^{1}$, Yamin Liu ${ }^{1}$, Die Ren ${ }^{1}$, Yating Ning ${ }^{1}$, Xiaofeng Li $^{1}$, Qin Zhou ${ }^{1}$ \\ and Bing $\mathrm{Li}^{1,4, *}$ \\ 1 Division of Molecular Nephrology and The Creative Training Center for Undergraduates, \\ The Ministry of Education Key Laboratory of Clinical Diagnostics, School of Laboratory Medicine, \\ Chongqing Medical University, Chongqing 400016, China; littlebottlesky@gmail.com (Y.G.); \\ xianzhaoya@gmail.com (Y.Z.); zhouyuru93@gmail.com (Y.Z.); yjxie@genetics.ac.cn (Y.X.); \\ 18883936591@163.com (P.J.); longyaoshui@gmail.com (Y.L.); liujianingb@gmail.com (J.L.); \\ dongshengni@outlook.com (D.N.); caofen7@gmail.com (F.C.); zhongshilyu@gmail.com (Z.L.); \\ maozhaomin8@gmail.com (Z.M.); lanyxiu@163.com (J.H.); liyimanb@gmail.com (Y.L.); \\ qy.wan@Outlook.com (Q.W.); quistmansa@gmail.com (Q.K.); liuyamin2013@126.com (Y.L.); \\ rendielittle@gmail.com (D.R.); ningyating@outlook.com (Y.N.); happylena18@gmail.com (X.L.); \\ zhouqin@cqmu.edu.cn (Q.Z.) \\ 2 Department of Laboratory Medicine, The First Hospital of Xi'an, Xi'an 710002, China \\ 3 Undergraduates Class of 2012 Entry, The Fifth Clinical College of Medicine, Chongqing Medical University, \\ Chongqing 400016, China \\ 4 The First Affiliated Hospital of Chongqing Medical University, Chongqing 400016, China \\ * Correspondence: libing@cqmu.edu.cn; Tel.: +86-23-6848-5785 \\ + These authors contributed equally to this work.
}

Academic Editor: Anthony Lemarié

Received: 17 April 2016; Accepted: 27 July 2016; Published: 6 August 2016

\begin{abstract}
Nephron progenitor cells surround around the ureteric bud tips (UB) and inductively interact with the UB to originate nephrons, the basic units of renal function. This process is determined by the internal balance between self-renewal and consumption of the nephron progenitor cells, which is depending on the complicated regulation networks. It has been reported that Zeb1 regulates the proliferation of mesenchymal cells in mouse embryos. However, the role of Zeb1 in nephrons generation is not clear, especially in metanephric mesenchyme (MM). Here, we detected cell proliferation, apoptosis and migration in MM cells by EdU assay, flow cytometry assay and wound healing assay, respectively. Meanwhile, Western and RT-PCR were used to measure the expression level of Zeb1 and Six 2 in MM cells and developing kidney. Besides, the dual-luciferase assay was conducted to study the molecular relationship between Zeb1 and Six2. We found that knock-down of Zeb1 decreased cell proliferation, migration and promoted cell apoptosis in MM cells and Zeb1 overexpression leaded to the opposite data. Western-blot and RT-PCR results showed that knock-down of Zeb1 decreased the expression of Six2 in MM cells and Zeb1 overexpression contributed to the opposite results. Similarly, Zeb1 promoted Six2 promoter reporter activity in luciferase assays. However, double knock-down of Zeb1 and Six2 did not enhance the apoptosis of MM cells compared with control cells. Nevertheless, double silence of Zeb1 and Six2 repressed cell proliferation. In addition, we also found that Zeb1 and Six2 had an identical pattern in distinct developing phases of embryonic kidney. These results indicated that there may exist a complicated regulation network between Six2 and Zeb1. Together, we demonstrate Zeb1 promotes proliferation and apoptosis and inhibits the migration of MM cells, in association with Six2.
\end{abstract}


Keywords: Zeb1; Six2; metanephric mesenchyme cells; cell proliferation; cell apoptosis; cell migration

\section{Introduction}

The kidney is a vital and complex organ that accomplishes multiple physiological functions in the body, such as metabolic waste excretion, water and electrolyte homeostasis control, acid-base balance and blood pressure maintenance. Nephrons is the major functional units for kidney to perform these tasks $[1,2]$. During kidney development, nephrons' formation is mainly decided by the interaction of the ureteric bud (UB) and metanephric mesenchyme (MM) cells [3,4]. It begins at embryonic day 10.5 (E10.5) to E11.0 when the UB starts growing and branching under the induction of MM cells [5], and MM cells aggregate around the branched tips of UB. Then, the MM cells and UB form nephrons by two cellular processes: MET and tubule genesis [6]. These reports indicate that MM cells are the original cells of nephron generation and inductively interact with UB in kidney development $[7,8]$. In addition, self-renewal (proliferation) and consumption of MM cells determine the formation and complement of nephrons $[8,9]$. Consequently, the proliferation, apoptosis and migration of MM cells become especially important in the study of kidney development.

Zeb1, a transcription factor containing 1117 amino acids, is an EMT marker in cancer metastasis of some tissues including kidney [10,11]. Zeb1 promotes EMT through suppression of CDH1 (encoding E-cadherin, an epithelial maker) and the microRNA-200 [10]. This process activates transforming growth factor- $\beta 1$ (TGF- $\beta 1$ ) signaling pathway and trigger cancer cell proliferation, invasiveness and stemness out of control [11,12]. In addition, Zeb1 also plays a critical role in animal organ development [13], cartilage development [14] and regulation of mesenchymal cell proliferation [15]. As an example, loss of Zeb1 results in MET and reduce the proliferation of progenitor cells at the sites of developmental defects in mouse embryos [15]. However, there is little reference about the concrete role of Zeb1 in the cellular regulation of MM cells.

Six2, a MET-marker, maintains cap mesenchyme multipotent nephron progenitor cells at an undifferentiated state, promotes MM cell proliferation and restrains cell apoptosis during kidney development $[8,9,16]$. Deficiency of Six 2 depletes cap mesenchyme progenitors, ectopic differentiation, and severe kidney hypoplasia and dysplasia $[17,18]$. However, EMT and MET are two distinct cellular processes that respectively function in cancer metastasis and development. Zeb1 and Six2 are the main markers of these two processes, respectively, but whether there exists a relationship between Zeb1 and Six2 in MM cells remains unknown.

Here, we found that Zeb1 promoted cell proliferation and migration, but suppressed cell apoptosis in MM cells, and Zeb1 can bind to Six2 promoter to regulate its transcription by dual-luciferase assay and bioinformatics analysis. Our RT-PCR and Western blot results showed that Zeb1 increased the expression of Six2. Both of Zeb1 and Six2 had a high expression level in embryonic kidney at E13.5 and E18.5. These discoveries provided theoretical evidence for further studying the role of Zeb1—regulated Six2 in kidney development.

\section{Results}

\subsection{Zeb1 Is Highly Conserved and Homologous across Different Mammalians}

To analyze the conservative of Zeb1 protein, we used CLUSTALW online [19]. The Zeb1 protein is highly conservative and homologous in evolution among mammal species such as Chimpanzee, Human, Rhesus monkey, Dog, Giant panda, Norway rat and House mouse (Figure 1A,B). Additionally, we compared the three types of Zeb1 function domains (seven $\mathrm{C} 2 \mathrm{H} 2$ zinc finger, three Zinc finger double domain and a Homeodomain) in NCBI Protein Database [20]. Then, we found that the structure of Zeb1 protein across those mammal species is also highly conserved (Figure 1C). 
A

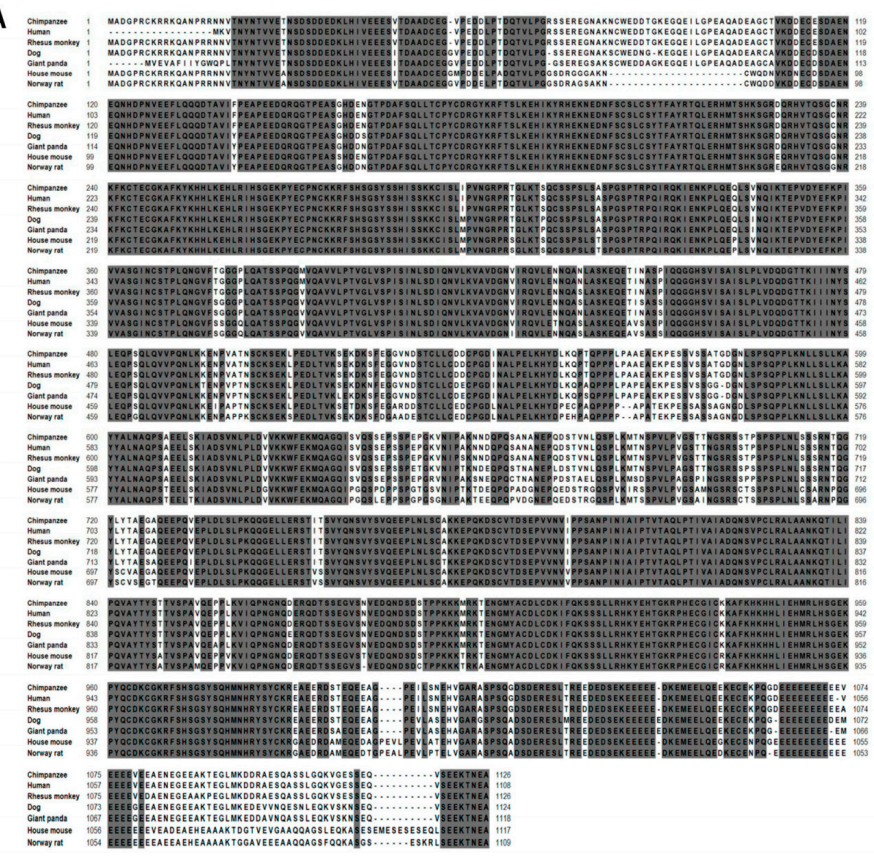

B

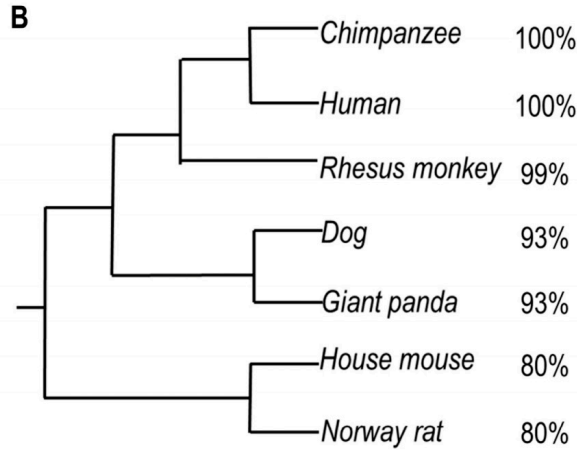

C

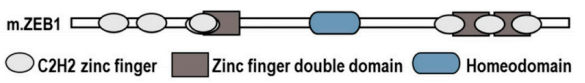

Figure 1. Bioinformatic analysis of Zeb1 protein. (A) Several tracks of entire amino acid sequences of Zeb1 across different mammal species. NCBI was used to get the sequences that were 1117aa in length and were highly conserved shown in gray shadow representing $100 \%$ matched sequences across different species; (B) Rooted phylogenetic tree (UPGMA) displayed Zeb1 is highly homologous among different mammalian. The identity is shown on the right; (C) Zeb1 protein structure contains seven $\mathrm{C} 2 \mathrm{H} 2$ zinc finger domains, three zinc finger double domains and one homeodomain.

\subsection{Zeb1 Promotes the Proliferation and Migration but Inhibits the Apoptosis of MM Cells}

As noted above, the function of Zeb1 in metanephric mesenchymal cells remains unclear during kidney development, so we wonder whether Zeb1 plays a crucial role in the regulation of these cells.

To investigate whether Zeb1 affects the proliferation, apoptosis and migration of MM cells, $\mathrm{mK} 3$ cells were used as a cell model. $\mathrm{mK} 3$ cells were transfected with Zeb1 overexpression or knock-down (Zeb1-shRNA) vector followed by EdU assay. As illustrated in Figure 2A,B and Figure A1, the ratio of EdU positive cells to the whole cells was promoted in $\mathrm{mK} 3$ cells transfected with the overexpression vector compared with the control. However, the ratio was reduced while Zeb1 was knocked down in mK3 cells. Meanwhile, to find out the effect of Zeb1 on cell apoptosis of the $\mathrm{mK} 3$ cells, we detected the apoptosis of $\mathrm{mK} 3$ cells transfected with Zeb1 overexpression vector, overexpression control vector, Zeb1-shRNA or control shRNA (pLKO.1). Then, mK3 cells transfected with Zeb1-shRNA or control shRNA (pLKO.1) were treated with $0.1 \mu \mathrm{M}$ dexamethasone before cell apoptosis analysis. Overexpression of Zeb1 decreased the rate of $\mathrm{mK} 3$ cell apoptosis compared with the control cells (Figure 3A,B). Besides, Zeb1 silence and dexamethasone treatment increased the apoptosis rate of $\mathrm{mK} 3$ cells and knockdown of Zeb1 increased cell apoptosis induced by dexamethasone compared with the respective control cells (Figure 3C,D). These results demonstrate that Zeb1 inhibits MM cell apoptosis.

In addition, we treated $\mathrm{mK} 3$ cells with the same methods used in the proliferation assay. Contrarily, we performed Wound Healing Assay and found that deficiency of Zeb1 resulted in the reduction of wound healing percentage compared with the control (Figure 4A,B). In contrast, mK3 cells transfected with the overexpression vectors shows promotion of cell healing percentage (Figure $4 \mathrm{~A}, \mathrm{C}$ ). To some degree, these data concludes that the migration of $\mathrm{mK} 3$ cells is advanced by Zeb1.

Moreover, to determine the efficiency of Zeb1 overexpression or knock-down, we conducted the RT PCR and Western-blot. As expected, Zeb1 was overexpressed and knocked down efficiently (Figure 2C,D). All these findings indicates that Zeb1 can promotes the proliferation of $\mathrm{mK} 3$ cells. 
A
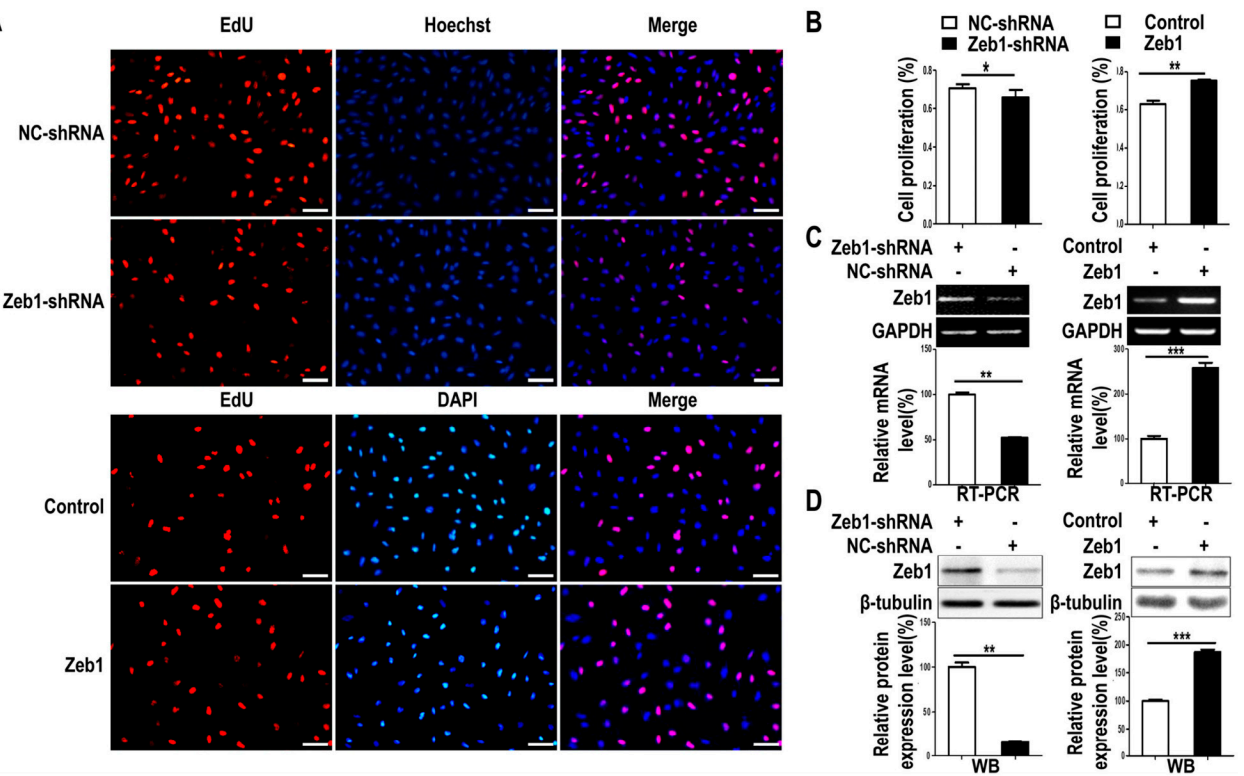

Figure 2. Knock-down of Zeb1 inhibits mK3 cell proliferation while overexpression of Zeb1 promotes it. (A) Proliferating mK3 cells were labeled with EdU (red) and nucleuses of the whole cells were stained with DAPI or hoechst (blue). The cells were $48 \mathrm{~h}$ post-treated with vectors of overexpression or target shRNA or the respective control vectors. The images present were taken by fluorescent microscopy $(200 \times)$ with a scale bar of $50 \mu \mathrm{m}$ and the red and blue images were merged to the purple ones; (B) EdU positive percentage (EdU \%) were quantified. Results were displayed as mean $\pm \operatorname{SD}(n=3)$. ${ }^{*} p<0.05,{ }^{* *} p<0.01,{ }^{* * *} p<0.001$ negative control vectors; (C,D) The RT-PCR and western-blot showed the significant efficiency of Zeb1 overexpression and knock-down. The expression was calculated by scanning gray in Image J software normalized to the internal mRNA control GAPDH or protein control $\beta$-tubulin. The result was shown with error bars representing mean $\pm \operatorname{SD}(n=3) .{ }^{*} p<0.05,{ }^{* *} p<0.01$, *** $p<0.001$.

A
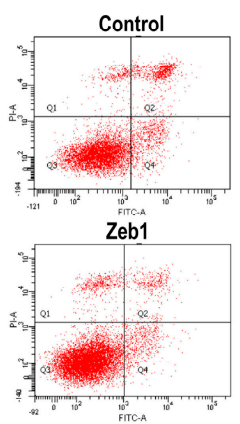

B

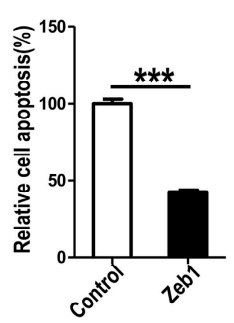

C

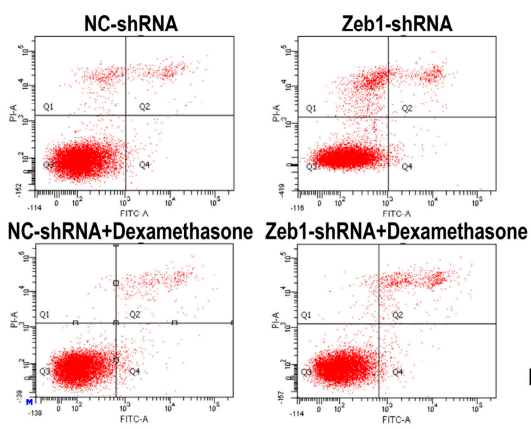

D

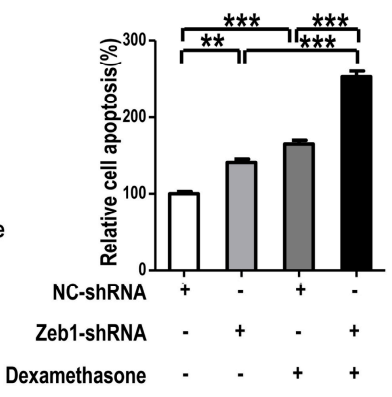

Figure 3. Knock-down of Zeb1 promotes $\mathrm{mK} 3$ cell apoptosis while overexpression of Zeb1 inhibits it. (A) $\mathrm{mK} 3$ cell apoptosis was detected by flow cytometry with Annexin V-FITC/PI staining. The number of positive cells double stained by AnnexinV-FITC/PI in mK3 cells transfected with Zeb1 overexpression vector was dramatically smaller than the control vector. The detection was performed $48 \mathrm{~h}$ transfection later; (C) mK3 cells were transfected with Zeb1-shRNA or negative control shRNA for $20 \mathrm{~h}$. Then one well cells of the two transfected with the same vector was treated with $0.1 \mu \mathrm{M}$ dexamethasone for $30 \mathrm{~h}$, following by cell apoptosis detection. The number of AnnexinV-FITC/PI-positive cells in Zeb1 knock-down mK3 cells was significantly larger than the negative control cells. And the dexamethasone at $0.1 \mu \mathrm{M}$ concentration increased the number of AnnexinV-FITC/PI-positive mK3 cells; (B,D) Apoptosis rates (Q2\% + Q4\%) of mK3 cells detected in Figure 3A,B were respectively quantified. Results were displayed as mean $\pm \operatorname{SD}(n=3)$. ${ }^{* *} p<0.01$, ${ }^{* * *} p<0.001$ negative control vector. 
A

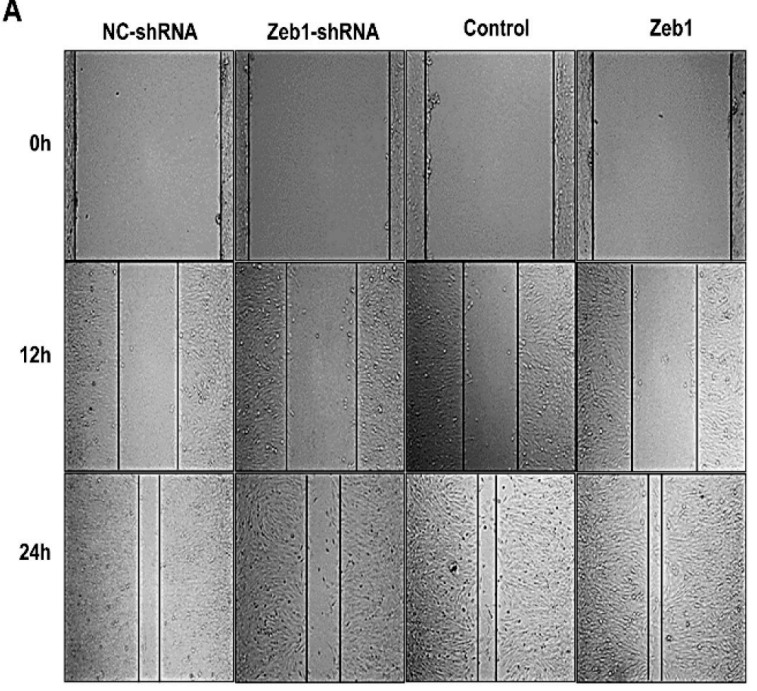

B

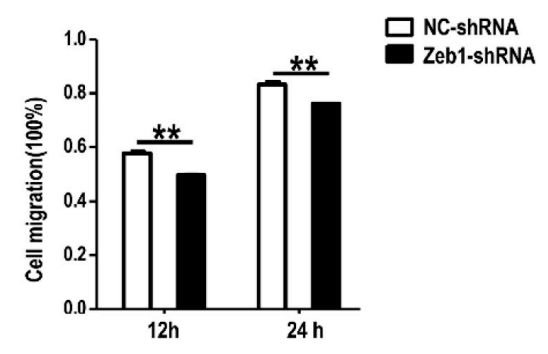

C

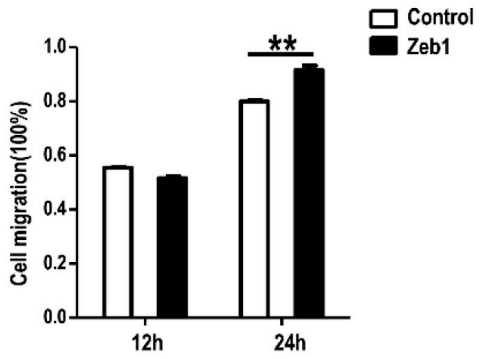

Figure 4. Knock-down of Zeb1 inhibits mK3 cell migration while overexpression of Zeb1 promotes cell migration only after $24 \mathrm{~h}$. (A) Cell migration of $\mathrm{mK} 3$ cells was measured via wound healing assay. The width of wound area was calculated at three time points $(0,12,24 \mathrm{~h})$ starting from the point when $\mathrm{mK} 3$ cells were transfected $48 \mathrm{~h}$ later. The transfection way was same with Figure 2. Zeb1 knock down led to lower apoptosis rate but Zeb1 overexpression resulted in higher rate, compared with the controls; (B,C) The quantification of wound healing percentage (100\%) was exhibited with the error bars representing mean $\pm \mathrm{SD}(n=3) .{ }^{* *} p<0.01$, negative control vector.

\subsection{Zeb1 Binds to Six2 Promoter and Up-Regulates Six2 in Metanephric Mesenchymal Cell}

To find out the mechanism of the cellular regulation in addition to metanephric mesenchymal cells, we performed bioinformatics prediction of the interaction between Zeb1 and Six2. As exhibited in Figure 5A, Zeb1 binding motifs towards the potential promoter of Six2 were conserved among mammal species such as Human, Chimpanzee, Mouse, Norway rat, Dog and Rhesus. This result shows it is possible that Zeb1 can regulate the expression of Six2 gene by mediating the transcription of Six2. Therefore, we carried out dual-luciferase assay, RT-PCR and Western blot to verify Zeb1 affected the expression of Six2. We found that overexpression of Zeb1 significantly promotes Six2 promoter reporter activity (Figure 5B). Additionally, the deficiency of Zeb1 up-regulated both mRNA and protein expression of Six2 compared with the control (Figure 5C). In contrast, Zeb1 overexpression caused the up-regulation of Six2 at both mRNA and protein level (Figure 5D). It has been reported that Six2 suppression inhibits cell proliferation, but promotes cell apoptosis in MM cells and up-regulation of Six2 promotes cell migration [8,17]. These previous studies can explain the phenotype of Zeb1.

\subsection{Zeb1 Regulates Cell Proliferation and Apoptosis of MM Cells by Working with Six2}

To clarify the interaction between Zeb1 and Six2 in metanephric mesenchymal cells' regulation, mK3 cells were transfected with negative control shRNA (pLKO.1), Zeb1-shRNA, Six2-shRNA or both Zeb1-shRNA \& Six2-shRNA followed by EdU assay and apoptosis detection. As shown in Figure 6A,B, mK3 cells introduced with either Zeb1-shRNA or Six2-shRNA made cell proliferation significantly reduced, compared with the negative control cells. Moreover, $\mathrm{mK} 3$ cells transfected with both of Zeb1-shRNA and Six2-shRNA presented a smaller ratio compared with the $\mathrm{mK} 3$ cells transfected with one of the two shRNA. These results declare that down-regulation of Six 2 restrains MM cell proliferation indeed and this suppression was enhanced when Zeb1 was knocked down with Six2 down-regulated (Figure 5C). 
A
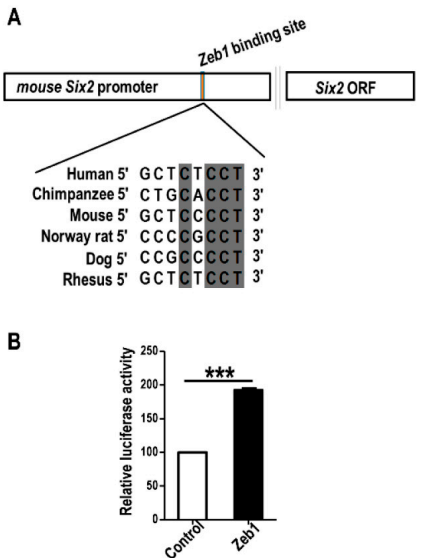
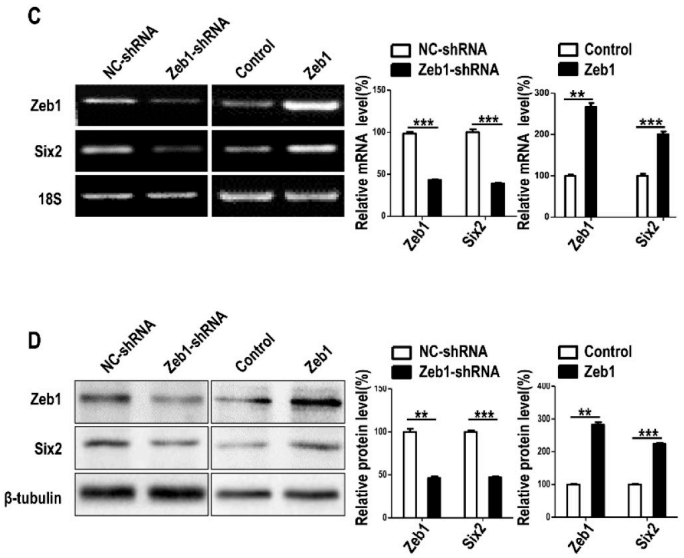

Figure 5. Zeb1 binds to Six 2 promoter and up-regulates Six2 in mK3 cells. (A) The predicted binding motifs of Zeb1 to Six 2 promoter, which was acquired from the JASPAR Database. The binding motifs across mammal species are conservatively shown in gray shadow representing the matched sequence among several mammal species, for instance, seven base pairs in eight were matched between mouse and human; (B) G401 cells were co-transfected with pGL-SV40 (renilla control), firefly luciferase reporter pcDNA3.1-Six2 promoter-luciferase, and either the m.Zeb1 expression plasmid pCDH-copGFP-m.Zeb1 or the respective control vector. Luciferase activity was assayed using dual luciferase reporter assay $48 \mathrm{~h}$ after transfection, normalized to renilla control. The result was analyzed by student's $t$ test and displayed with error bars representing mean $\pm \operatorname{SD}(n=3)$, ${ }^{* *} p<0.01$, ${ }^{* * *} p<0.001$; (C,D) RT-PCR was used to detect the expression of Six 2 at both mRNA and protein level. Six 2 was remarkably decreased in $\mathrm{mK} 3$ cells treated with Zeb1-shRNA compared with negative control shRNA. Overexpressing Zeb1 in $\mathrm{mK} 3$ cells led to the promotion of Six 2 expression at mRNA level. The expression was quantified by scanning gray in Image J software normalized to the internal mRNA control 18S or protein control $\beta$-tubulin. The result was displayed with error bars representing mean $\pm \operatorname{SD}(n=3),{ }^{* *} p<0.01$, *** $p<0.001$.

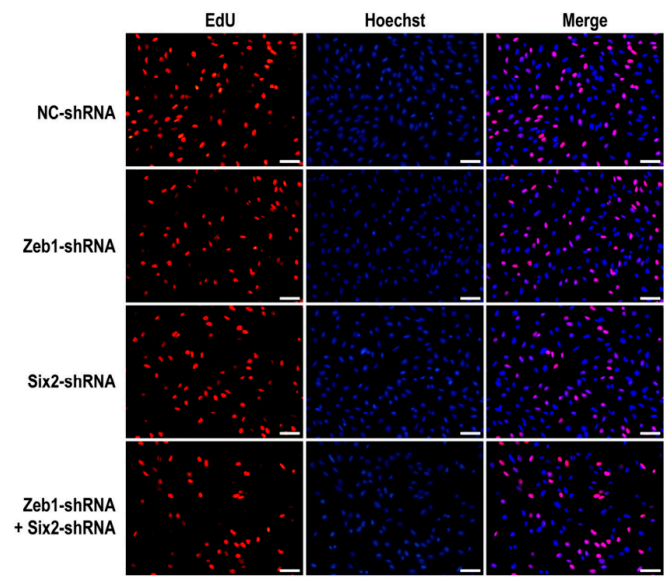

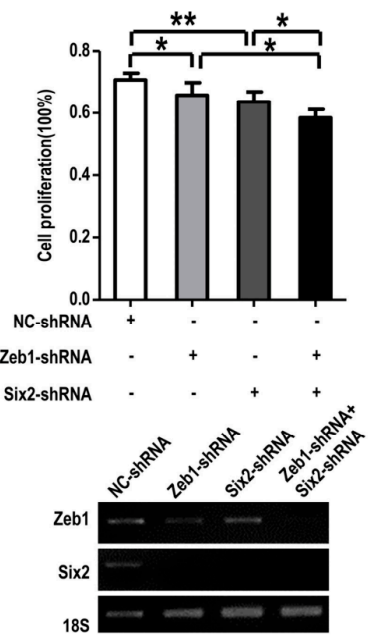

Figure 6. Zeb1 is required for the proliferation of $\mathrm{mK} 3$ cells associated to Six2. (A) $\mathrm{mK} 3$ cells were $48 \mathrm{~h}$ post-introduced with control shRNA, Zeb1-shRNA, Six2-shRNA or both of the two target shRNA. Then EdU assay was performed refering to Figure 2 and the red and blue images were merged to the purple ones; the length of scale bar was $50 \mu \mathrm{m}$. Cell proliferation was decreased in $\mathrm{mK} 3$ cells treated with either single shRNA or double shRNA of Zeb1 and Six 2 compared with respective controls; (B) The data of proliferation percentage (EdU \%) were presented as mean $\pm \operatorname{SD}(n=3) .{ }^{*} p<0.05$, ** $p<0.01$, respective controls; (C) The significant knock-down efficiency of Zeb1 and Six2 was measured by the RT-PCR with the internal control $18 \mathrm{~S}$ equal. 
What is more, we performed cell apoptosis detection in mK3 cells treated the same as in Figure 6. For cell apoptosis, when mK3 cells were introduced with either Zeb1-shRNA or Six2-shRNA, the rate of cell apoptosis was higher than the control cells. However, it is found that $\mathrm{mK} 3$ cells introduced with both of the two shRNAs had a lower apoptosis rate, compared with that transfected by only one shRNA (Figure 7A,B). From these data, it is implied that there is interaction between Zeb1 and Six2 in the apoptosis regulation of MM cells. The complicated relationship leads to the different apoptosis trends between single-knock-down of Zeb1, Six2 and double-knock-down of both.

A
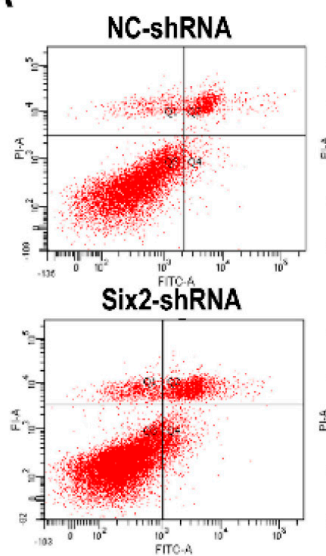
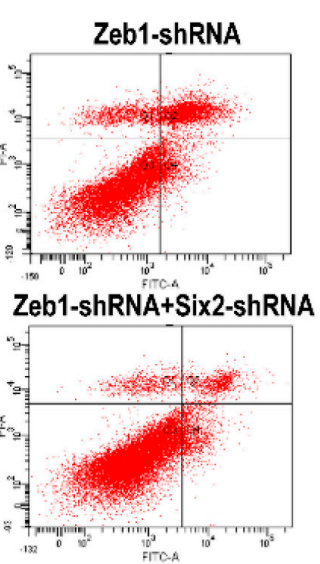

B

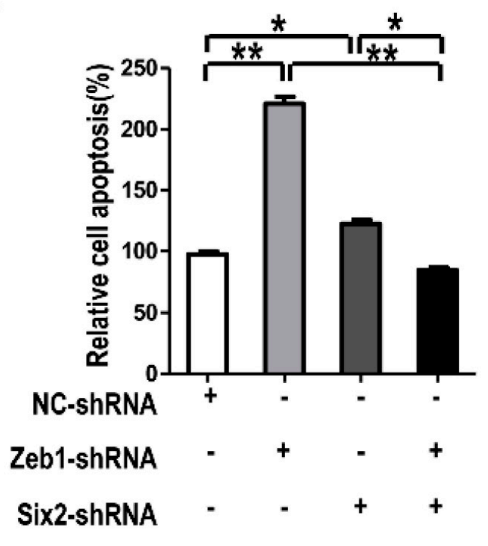

Figure 7. Zeb1 is required for mK3 cells to survival associated with Six2. (A) mK3 cells were transfected same with Figure 6 and cell apoptosis was detected by reference to Figure 3. The rate of apoptosis in $\mathrm{mK} 3$ cells treated with single target shRNA is higher than the negative control shRNA, while mK3 cells treated double shRNAs had a lower rate than the single targeted $\mathrm{mK} 3$ cells; (B) Cell apoptosis rate was quantified and presented as mean $\pm \mathrm{SD}(n=3) .{ }^{*} p<0.05,{ }^{* *} p<0.01$, respective controls.

Meanwhile, to confirm Zeb1 mediates cell phenotypes above by affecting the expression of Six2, we quantified the mRNA expression of Six 2 by RT-PCR. As illustrated in Figure 6C, the knock-down of Zeb1 or Six2 was all efficient and Zeb1 knock-down significantly down-regulated Six2 expression at the mRNA level.

\subsection{The Expression Profile of Zeb1 and Six2 in Kidney Development}

As mentioned above, we found Zeb1 mediated cell proliferation, apoptosis and migration in MM cells associated with Six2, which was fundamental for kidney development. Thus, we wonder whether Zeb1 or Six2 was expressed differently in variant stages during kidney development. Accordingly, we conducted RT-PCR using cDNAs of embryonic mouse kidney at different times (E11.5, E12.5, E13.5, E14.5, E16.5, E18.5). As diagramed in Figure 8A,B, the mRNA expression of Zeb1 and Six2 changed with the kidney development stage, and the variant tendency of Zeb1 and Six2 was identical except for E16.5. This finding suggests that Zeb1 quite possibly plays an important role during kidney development in relation to Six2. Furthermore, we conducted the expression prediction of Zeb1 and Six2 by GUDMAP online to analyze Zeb1 and Six 2 mRNA expression at different times, which presented variant mRNA levels (Figure $8 \mathrm{C}$ ).

\section{6. c-Myc Is Up-Regulated by Zeb1 in MM Cells}

To verify the mechanism that Zeb1 mediates MM cells by regulating Six2, we checked the protein expression of c-Myc, a transcription factor that has been reported to have interaction with Six2 during nephrogenesis [21]. The Western-blot data showed that the deficiency of Zeb1 down-regulated c-Myc (Figure 9A,B) and Zeb1 overexpression led to the up-regulation of c-Myc (Figure 9C,D). 
A

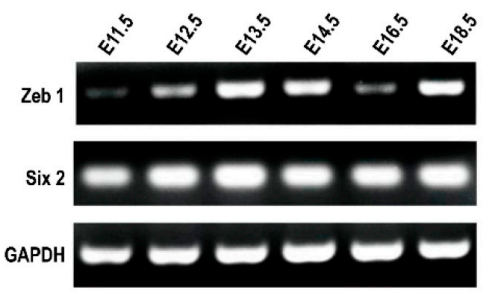

B

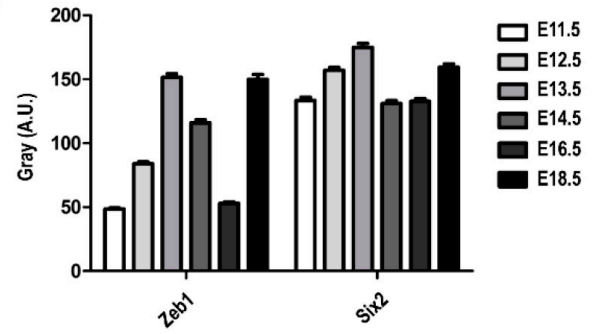

C

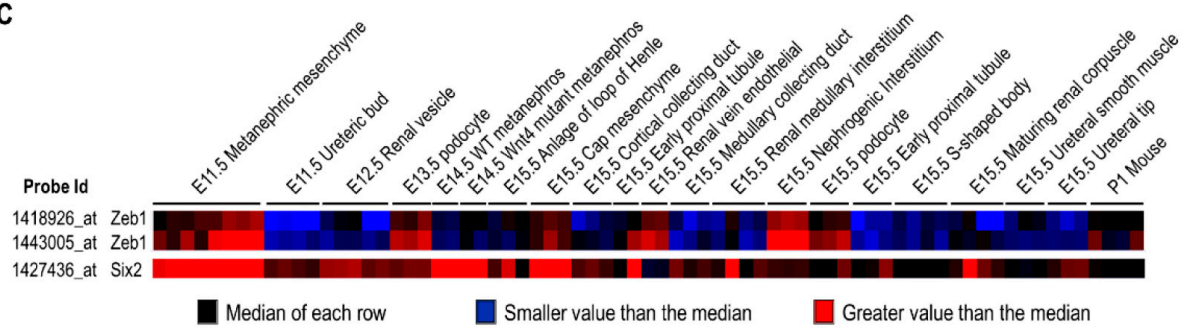

Figure 8. Zeb1 and Six2 have a similar expression profile in mouse kidney development. (A) RT-PCR was performed using the cDNA library obtained from the embryonic mouse kidney at different embryonic days (E11.5, E12.5, E13.5, E14.5, E16.5, E18.5). The mRNA expression of both genes showed identical variation trends except for E16.5; (B) The quantification was analyzed by Gray Scan normalized to the internal control GAPDH and the results were acted as mean $\pm \mathrm{SD}(n=3)$; (C) Bioinformatics analysis of Zeb1 and Six 2 mRNA expression was performed in GUDMAP Expression Database. It is the microarray data in different cells of developing renal, in which blue represents the median of each row, black means the expression value is smaller than median, while red represents a larger value.
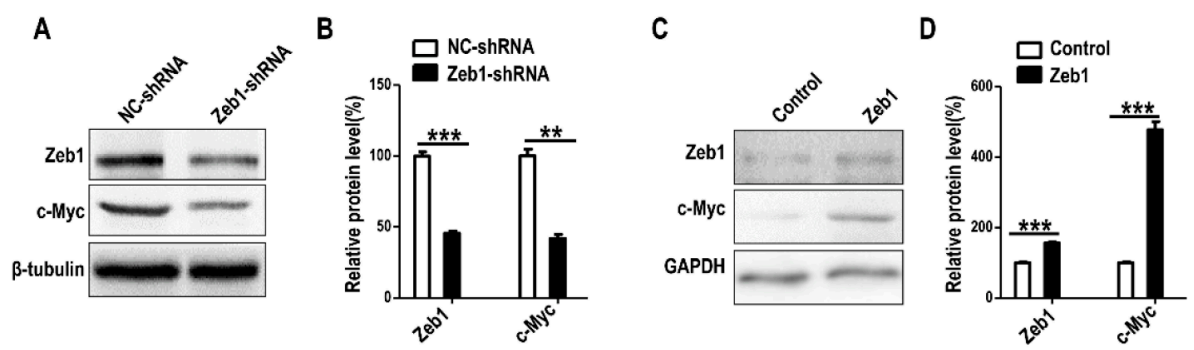

Figure 9. The expression of c-Myc in $\mathrm{mK} 3$ cells is regulated by Zeb1. (A) Western visualization shows that $\mathrm{mK} 3$ cells introduced with Zeb1-shRNA for $48 \mathrm{~h}$ expressed c-Myc less than cells treated with control shRNA at protein level; (B) The expression was calculated by scanning gray in Image J software normalized to the internal control GAPDH. The result was displayed with error bars representing mean $\pm \mathrm{SD}(n=3) .{ }^{* *} p<0.01,{ }^{* *} p<0.001$; (C) The protein expression of c-Myc was increased in $\mathrm{mK} 3$ cells treated with Zeb1 overexpression for $48 \mathrm{~h}$ compared with the control cells (blank vector); (D) The expression was quantified the same way as in (B).

\section{Discussion}

Zeb1, a transcription factor, is highly conserved and homologous in evolution among different species at the protein level. Here, we first reported the role of Zeb1 in kidney development and its cellular function in MM cells. Knock-down of Zeb1 decreased cell proliferation and migration, but increased cell apoptosis in MM cells (Figures 2-4 and Figure A1). Deficiency of Zeb1 down-regulated the expression of Six2 and c-Myc (Figure 5C,D and Figure 9A,B). Moreover, overexpression of Zeb1 promotes Six2 promoter reporter activity in luciferase assay (Figure 5B). On the contrary, overexpression of Zeb1 leads to the opposite results (Figures 2-4, Figure 5C,D and Figure 9C,D). However, double knock down of Zeb1 and Six2 decreased cell proliferation more seriously 
(Figure 6A,B), but did not enhance cell apoptosis in MM cells compared with Six2 or Zeb1 knockdown alone (Figure 7A,B).

Metanephric mesenchyme (MM) cells include the nephron progenitor cells marked by Six2 and form nephrons by balancing self-renewal and consumption [7,9]. Numerous transcription factors are involved in this process, such as c-Myc and Six2 [8,17]. In this study, we focused on a transcription factor Zeb1, which is widely expressed in development and cancer and acts as an inducer of EMT and a regulator of cell migration in cancer cells [10]. In addition, mutation of Zeb1 can induce MET and reduce the proliferation of progenitor cells at defects sites of developing mouse embryos [22]. Besides, knock-down of Zeb1 inhibits cell growth via activating the apoptosis pathway [23], and TXNIP/miR-200/Zeb1/E-cadherin signaling pathway is reported to function in beta cell apoptosis [24], which suggests that Zeb1 plays a crucial role in cell apoptosis. Meanwhile, our results suggested that the resistant of Zeb1-depleted $\mathrm{mK} 3$ cells to dexamethasone are decreased in comparison to control cells, which implied that $Z e b 1$ is involved in the apoptosis process that is induced by agent dexamethasone (Figure 3C,D). So, we speculate that Zeb1 may be a regulator of MET and had an association with MET marker-Six2 in MM cells.

Interestingly, knock-down of Zeb1 decreased cell proliferation and migration but increased cell apoptosis in MM cells as reported in other cells [10,22]. Furthermore, the expression of Six2 was down-regulated when Zeb1 was knocked down. Down-regulation of Six2 represses MM cell proliferation and migration $[16,18]$ but enhances cell apoptosis [8], and overexpression of Zeb1 leads to the opposite results, reasonably. These suggested that Six2 is involved in the process that Zeb1 mediated cell proliferation, migration and apoptosis in MM cells. As is known to us, Six2 is an essential gene in kidney development and its expression is variant during renal development [25]. We further measured the mRNA expression of Six2 and Zeb1 in embryonic mouse kidney in vitro (Figure 8A,B). Although their expression pattern is not completely the same, both of Six2 and Zeb1 had high expression at the E11.5 to E13.5 stage, which is a key period in the mouse kidney development process. It has been reported that, in the process of mammalian cell apoptosis, caspases mediate 500-1000 proteins' cleavage and generate many protein fragments, which can increase the probability of cell apoptosis [26-28]. Nevertheless, there are some reports that N-terminal truncated Lyn $\Delta \mathrm{N}$ that is generated by caspase cleavage has been demonstrated with anti-apoptotic roles [29]. Whatever the concrete role of this fragment in cell apoptosis is, these reports provide a direction for our subsequent study about Zeb1, Six 2 and cell apoptosis in embryonic mouse kidney development. Here, our results demonstrated that Zeb1 depletion decreased Six 2 expression and enhanced cell apoptosis in mk3 cells, but the connection between Six 2 down-regulation and cell apoptosis promotion remains unknown. Because of the limit of time and materials, we did not test the protein expression of Zeb1 and Six 2 in embryonic mouse kidney in the present study, but we will detect their protein level and further study the connection between Six 2 down-regulation and cell apoptosis promotion during embryonic mouse kidney development. Interestingly, the recent study shows that Zeb1 can positively regulate the mTOR pathway and maintain its threshold level in wild-type MEFs that is required for Akt-S473 generation [30], and mTOR pathway can rescue many developmental defects of embryos due to the ESCO2 mutant [31], which indicates that the mTOR pathway is essential in development. All these studies indicate that mTOR pathway may be involved in Zeb1-regulated renal development.

To find out the regulatory mode between Zeb1 and Six2, we combined the bioinformatics analysis with the dual-luciferase assay results and found that Zeb1 could bind to Six 2 promoter to enhance the luciferase activity. Therefore, these may prove that Zeb1 binds to Six2 promoter to promote Six 2 gene transcription and further promotes gene expression, which is identical to the up-regulation of Six2 in Zeb1 overexpressed cells. All these indicated that Zeb1 might up-regulate Six2 by transcriptional regulation. Perhaps post-translational modification is another regulation mode, which provides us valuable insight for further research on the regulation mechanism between Zeb1 and Six2.

To make the mechanism clear, we detected the expression of c-Myc, a member of the Myc family of proto-oncogenes expressed in the MM progenitors and which are essential for progenitor cell 
proliferation and kidney growth [32,33]. Then, we found that a deficiency of Zeb1 down-regulated c-Myc and overexpression of Zeb1 up-regulated c-Myc in MM cells (Figure 9A-D). Zeb1 represses the expression of miR-34a and $\mathrm{miR}-34 \mathrm{~b} / \mathrm{c}$, and miR-34a conversely down-regulated Zeb1 and c-Myc to decrease the migration and invasion of cancer cells [34]. Furthermore, Six 2 mediates the nuclear translocation of Eya1, then Eya1 switches Myc between phosphorylation and dephosphorylation states to regulate MM cell multipotency, proliferation, apoptosis, and so on [21]. Deletion of c-Myc can reduce Six2-positive stem/progenitor populations and decrease cell proliferation [33]. Therefore, these evidences demonstrated Six 2 and c-Myc may be new targets of Zeb1. However, the role of c-Myc needs to be clarified in further study, and elucidating the regulation network among them appears especially important in kidney development.

Based on our results and the reported data, we formed a work model to illustrate the regulation between Zeb1 and Six2 during embryonic renal development (Figure 10). Zeb1 promotes MM cell proliferation (cell renewal) and cell migration but inhibits cell apoptosis (cell consumption) in association with Six2 up-regulation and c-Myc down-regulation. The MM cell renewal, consumption and migration are essential for the induced interaction between MM cells and UB. These contribute to UB branching morphogenesis and MET and elongation for nephrons' formation in embryonic kidney development. Besides, Zeb1 and Six2 have similar expression patterns at different stages of developing kidney (Figure 8A,B). These results further suggested that $Z e b 1$ is a potential regulator of Six2 and $\mathrm{c}-\mathrm{Myc}$ in the proliferation, migration and apoptosis of MM cells.

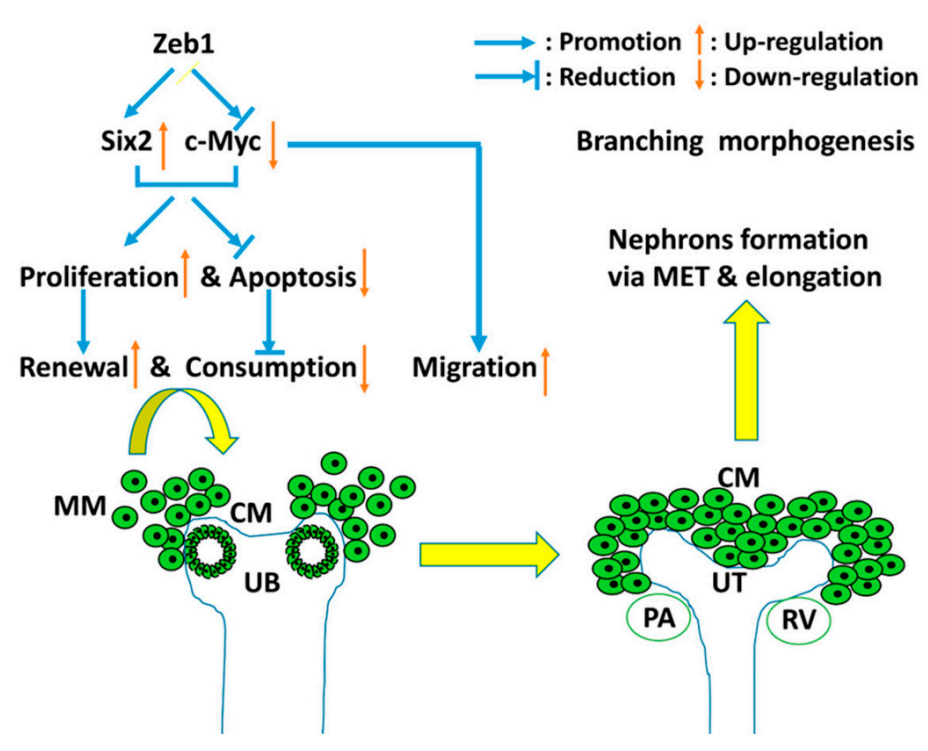

Figure 10. The work model of Zeb1 in developing embryonic kidney. Zeb1 promotes MM cell proliferation (cell renewal), cell migration but inhibits cell apoptosis (cell consumption) in association with Six2 up-regulation and c-Myc down-regulation. As the green cycles show, MM cells migrate and aggregate at UB branches with the induction of UB, then interact with UB. So the MM cell renewal, consumption and migration are essential for the induced interaction between MM cells and UB. These contributes to UB branching morphogenesis and MET and elongation for nephrons formation during embryonic kidney development.

\section{Materials and Methods}

\subsection{Bioinformatic Analysis}

The species and evolutionary conservation of Zeb1 proteins was analyzed using Multiple Sequence Alignment by CLUSTALW online [19] and edited in BioEdit software. The amino acid sequences used for analysis were acquired from the NCBI GenPept Database [20]. Moreover, gene expression pattern (Developing Kidney MOE430 Microarray Analysis) of Zeb1 and Six2 was obtained from the GUDMAP 
Expression Database [35]. Additionally, the motifs where Zeb1 may bind to Six2 potential promoter (2000bp upstream of transcription start site) was predicted on the JASPAR Database [36], the six promoter sequence (NCBI reference sequence NC_000083.6) was retrieved from the Genbank Database.

\subsection{Plasmids Construction}

The m.Zeb1 CDS was amplified from the cDNA of C57BL/6 embryonic mouse kidney by PCR using the forward primer: $5^{\prime}$-tagcgtttaaactta GATCATGGCGGATGGCCCCAGG TGTAAGC-3', the reverse primer: $5^{\prime}$-tggactagtggatcc CTAAGCTTCATTTGTCTTCTCTTCA- $3^{\prime}$. The amplification was inserted into the HindIII/BamHI site of pCDNA3.1 (+) (Invitrogen, Carlsbad, CA, USA) using the ligation-independent cloning (LIC) $[37,38]$. Then the m.Zeb1 CDS fragment was cut by the NheI/BamHI restriction enzyme and was cloned to the pCDH-CMV-MCS-EF1-copGFP vector (a lentivirus overexpression vector) at the same restriction site using T4 ligation cloning. The m.Zeb1 shRNA and m.Six 2 shRNA sequences were acquired from the SIGMA ALORICH [39] with m.Zeb1 target: 5'-CCGGGTCAGTAAACATACCTA-3'; m.Six 2 target: 5'-CCTCCACAAGAATGAAAGCGT-3' . Then anneal the shRNA oligo containing gene target and clone the annealed fragment to pLKO.1 vector at AgeI/EcoRI site according to the protocols [40] pGL3-basic vector (Promega, Madison, WI, USA) and pRL-SV40 was purchased from Promega. The promoter of murine Six2 was amplified from C57BL/6 mouse genomic DNA by PCR using the forward primer: CGTGCTAGCCCGGGCTATTTCCCAGGTCCCCTGGAATCCT and the reverse primer: CCGGAATGCCAAGCTCTTGCAGCTTTTTTAATAATATTAT. Then the fragment was inserted into the XhoI/HindIII site (upstream of fly luciferase gene) of the pGL3-luciferase vector to create pGL3-Six2 promoter-luciferase using LIC. All of these recombined vectors were sequenced and aligned in the NCBI Nucleotide Blast Database.

\subsection{Cell Culture and Transfection}

The 293T cell and mK3 cell (a cell line cloned from mouse and representing the un-induced differentiation stage of metanephric mesenchyme [41,42]) were cultured in DMEM medium (Gibico, Carlsbad, CA, USA) with 10\% FBS (Gibico, Carlsbad, CA, USA), 1000 units/mL of penicillin and $1000 \mu \mathrm{g} / \mathrm{mL}$ of streptomycin in $37^{\circ} \mathrm{C}, 100 \%$ humidity and $10 \% \mathrm{CO}_{2}$. The G401 cell were cultured in the same condition except the different base medium ATCC-formulated McCoy's 5a Medium Modified (Cat. No.30-2007, ATCC). When the mK3 cell grew to 60\% confluent in 6-well plates, lentivirus mediated cell transfection was performed, with the assist of polybrene $(8 \mu \mathrm{g} / \mathrm{mL})$. The lentivirus was packed in HEK293T cell line with $10 \mu \mathrm{g}$ recombined vector in $10 \mathrm{~cm}$ dish, then it was harvested to infect $\mathrm{mK} 3$ cells after $48 \mathrm{~h}$. The pCDH-CMV-MCS-EF1-copGFP-m.Zeb1 CDS, pLKO.1-m.Zeb1 shRNA, pLKO.1-m.Six 2 shRNA and the corresponding control vectors were transfected alone while the m.Zeb1 shRNA was co-transfected with the m.Six 2 shRNA in another well.

\subsection{RNA Extraction and RT-PCR}

The total RNA was isolated using Trizol reagent (Invitrogen, Carlsbad, CA, USA) from $48 \mathrm{~h}$ post-transfected $\mathrm{mK} 3$ cells and the kidneys of C57BL/ 6 embryonic mice at different developmental stage. The cDNA was synthesized using the Invitrogen RT kit according to the manufacturer's protocol (Invitrogen). The mRNA expression level of Zeb1, Six2 was detected by RT-PCR at $60^{\circ} \mathrm{C}$ annealing temperature with Zeb1 real time PCR sense primer: $5^{\prime}$-CGAGTCAGATGCAGAAAATGAGCAA-3' and the anti-sense primer: $5^{\prime}$-ACCCAGACTGCGTCACATGTCTT- $3^{\prime}$; Six 2 sense primer: $5^{\prime}$-GCCTGCG AGCACCTCCACAAGAAT- $3^{\prime}$ and the anti-sense primer: $5^{\prime}$-CACCGACTTGCCACTGCCATTGAG-3' . The expression were normalized to the internal control (18s or GAPDH) and were quantified by Gray Scan using Image J software. 


\subsection{Western Blotting}

$\mathrm{mK} 3$ cells that were transfected for $48 \mathrm{~h}$ in 6-well plates were washed with PBS, pH 7.4 three times. Then, the cells were lysed with $300 \mu \mathrm{L}$ of $1 \%$ SDS lysis buffer. The lysed complex were collected and boiled at $95^{\circ} \mathrm{C}$ in a water bath for $10 \mathrm{~min}$ followed by centrifuging at $12,000 \mathrm{rpm}$ for $10 \mathrm{~min}$ to gather the proteins in supernatant. The concentration of proteins was measured using the Pierce BCA Protein Assay Kit (Thermo Scientific, Waltham, MA, USA) based on the manufacturer instructions. $30 \mu \mathrm{g}$ of each sample was used to conduct western in reference to the previous studies $[8,43]$. The primary antibodies respectively against Six2, Zeb1, c-Myc, $\beta$-tubulin were efficient with proper dilution (1:700; 1:800; 1:1000; 1:4000; Proteintech, Chicago, IL, USA).

\subsection{5-Ethynyl-2'-deoxyuridine (EdU) Assay}

mK3 cells were transfected with Zeb1 overexpression vectors or Zeb1-shRNA vectors or co-transfected with Zeb1-shRNA and Six2-shRNA vectors by lentivirus. Forty-eight hours later, the treated $\mathrm{mK} 3$ cells were seeded onto 96-well plates (10 thousand cells each well) and grew for about $8 \mathrm{~h}$ so that the cells were well adherent. Then the proliferation of $\mathrm{mK} 3$ cells was detected using the EdU DNA Proliferation in Detection kit (RiboBio, Guangzhou, China) according to the manufacturer instructions.

\subsection{MTT Assay}

The MTT assay was carried out to test the changes of cellular viability. About $2000 \mathrm{mK} 3$ cells transfected with Zeb1-shRNA or NC-shRNA were seeded in 96-well plates with five replicates. $12 \mathrm{~h}$ and $24 \mathrm{~h}$ later, the medium was aspirated, the cells were incubated with $100 \mu \mathrm{L}$ fresh medium containing $0.5 \mathrm{mg} / \mathrm{mL}$ MTT for $4 \mathrm{~h}$. Then, the medium was discarded and $100 \mu \mathrm{L}$ of dimethyl sulfoxide was added into the well to dissolve the resulting formazan crystals. The absorbance was detected using a microplate reader (MULTISKAN GO, Thermo Scientific, Waltham, MA, USA) at a test wavelength of $590 \mathrm{~nm}$. The average intensity of absorbance in relation to the formazan product indicated the number of cultured living cells with the equal cells at $0 \mathrm{~h}$.

\subsection{Flow Cytometry Assay and Reagent}

The apoptosis of mK3 cells was determined via the Annexin V-fluorescein isothiocyanate (FITC) Apoptosis Detection Kit (KeyGEN BioTECH, Nanjing, China). mK3 cells were transfected when the cells grew to about $60 \%$ confluence and $0.1 \mu \mathrm{M}$ dexamethasone was selected as an inducing

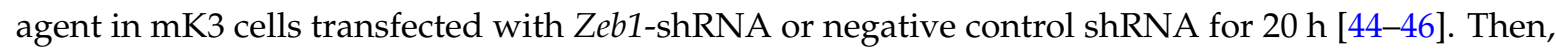
the cells were harvested $48 \mathrm{~h}$ later with EDTA-free trypsin. The cells were numbered by cell counting board and pipetted about 1 million for the later treatment according to the manufacturer instructions. The flow cytometry apoptosis detection was operated by the Institute of Pediatrics in Children's Hospital of Chongqing Medical University.

\subsection{Wound Healing Assay}

mK3 cells were plated in 6-well plates in Dulbecco's modified Eagle's medium (DMEM) supplemented with 10\% FBS. When cells confluence reached about 60\%, pCDH-copGFP-Zeb1 CDS, pLKO.1-Zeb1-shRNA, or blank vector (pCDH-copGFP or pLKO.1) were introduced into mK3 cells. The monolayer cells were generated scratch wounds using a pipette tip when cells grew to $95 \%-100 \%$, then washed twice with PBS, pH 7.4 to wipe off cell debris. Cells were incubated in completed DMEM in $37^{\circ} \mathrm{C}, 100 \%$ humidity and $5 \% \mathrm{CO}_{2}$. The images of wound width were taken at different time points (12 and $24 \mathrm{~h}$ ) using a fluorescence microscope (ECLIPSE Ti-s, Nikon, Tokyo, Japan). Four images were collected from independent selected fields of each sample, and the width of wound areas were calculated by 2014 Microsoft PowerPoint. 


\subsection{Dual-Luciferase Assay}

The G401 cell (a human tumor epithelial cell of Caucasian male, aging 3 months) were cultured in 24-well plate (0.1 million each well) for $24 \mathrm{~h}$ and then transiently co-transfected with pCDH-m.Zeb1, pGL3-Six2 promoter-luciferase (500 ng/well) and plasmid pRL-SV40 (10 ng/well) utilizing Polyetherimide (PEI) (23966-2, polysciences, Warrington, PA, USA). $48 \mathrm{~h}$ later, luciferase activity was assayed using Dual-Luciferase Reporter assay kit (Promega). Levels of firefly luciferase were standardized to those of Renilla.

\subsection{Embryonic Mouse Kidney Isolation}

Embryonic kidneys were isolated from the C57BL/ 6 mouse embryos at different developmental stage (E11.5, E12.5, E13.5, E14.5, E16.5, E18.5) as described [47]. The process was performed in PBS, pH 7.4 under a microscope and the kidneys were stored at $-80^{\circ} \mathrm{C}$ or put in Trizol solution for total RNA extraction.

\subsection{Statistical Analysis}

All experiments were performed independently three times and the results were presented as the mean \pm standard error of the mean (SEM) or SD. Data were assessed for the statistical significance using student's $t$ test. The GraphPad Prism 5 software (GraphPad, San Diego, CA, USA) was used to evaluate the statistical results. Statistical differences were considered significant with ${ }^{*} p<0.05$, ${ }^{* *} p<0.01,{ }^{* * *} p<0.001$.

\section{Conclusions}

The results shown in this study indicate that Zeb1 up-regulates Six2 and promotes proliferation and apoptosis and inhibits the migration in MM cells.

Acknowledgments: We sincerely thank for the support of the National Natural Science Foundation of China (Grant No. 31271563 and Grant 81572076) to Qin Zhou and the National Basic Research Program of China (No. 2011CB944002) to Qin Zhou. We also acknowledge the materials support of the Students Innovation Laboratory of Chongqing Medical University. And we thank for the ScienLab team, an entrepreneur team of undergraduate students, for their help of lentivirus packing.

Author Contributions: Yuping Gu, Ya Zhao, Yuru Zhou, Yajun Xie Qin Zhou and Bing Li conceived and designed the experiments; Yuping Gu, Pan Ju, Yaoshui Long, Dongsheng Ni, Jianing Liu and Fen Cao performed the experiments, Zhongshi Lyu, Zhaomin Mao analyzed the data; Jin Hao, Yiman Li, Quist Kanyomse, Qianya Wan, Yamin Liu, Die Ren, Yating Ning and Xiaofeng Li contributed reagents/materials/analysis tools; Yuping Gu, Ya Zhao, Yuru Zhou, Yajun Xie, Qin Zhou and Bing Li wrote the paper.

Conflicts of Interest: The authors declare no conflict of interest.

\section{Abbreviations}

$\begin{array}{ll}\text { Zeb1 } & \text { Zinc finger E-box-binding homeobox } 1 \\ \text { MM } & \text { Metanephric mesenchymal } \\ \text { UB } & \text { Ureteric bud } \\ \text { PA } & \text { Pre-tubular aggregate } \\ \text { UT } & \text { Ureteric tree } \\ \text { RV } & \text { Renal vesicles } \\ \text { CM } & \text { Condensed/cap mesenchyme } \\ \text { TGF- } \beta & \text { Transforming growth factor- } \beta \\ \text { FITC } & \text { Fluorescein isothiocyanate fitc } \\ \text { HEK } & \text { Human embryonic kidney } \\ \text { MET } & \text { Mesenchymal-epithelial-transition } \\ \text { EMT } & \text { Epithelial- mesenchymal-transition } \\ \text { DMEM } & \text { Dulbecco's modified Eagle's medium }\end{array}$




\section{Appendix A}

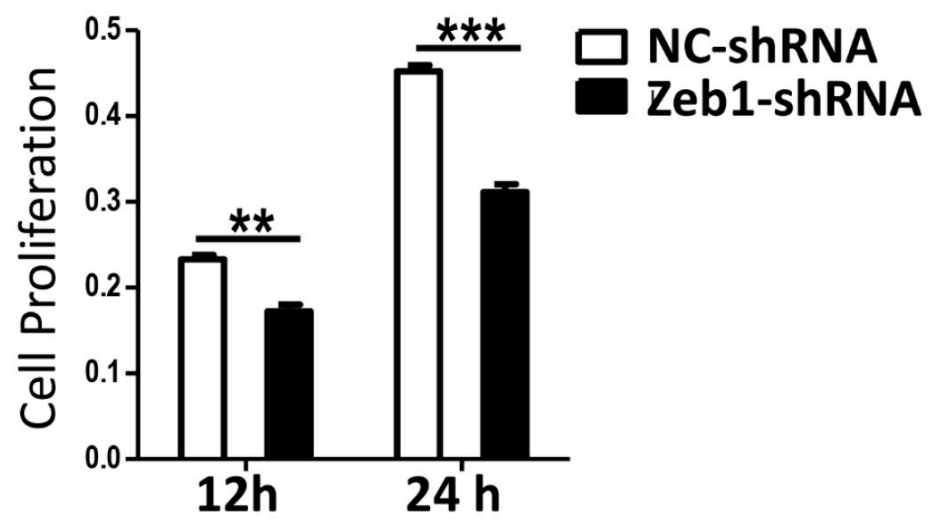

Figure A1. Knock-down of Zeb1 inhibits mK3 cell proliferation. mK3 cells were $48 \mathrm{~h}$ post-treated with vectors of target shRNA or the respective control vector, then the equal 2000 cells were seeded into the 96-well. Proliferating mK3 cells were tested in living cells using MTT at 12 and $24 \mathrm{~h}$. The formazan product was detected by the intensity of absorbance at $590 \mathrm{~nm}$ wavelength to indicate cell vitality. The absorbance intensity of Zeb1 knocked down cells was smaller than the negative control cells at both 12 and $24 \mathrm{~h}$. The absorbance present were examined by a microplate reader and results were displayed as mean $\pm \mathrm{SD}(n=3){ }^{* *} p<0.01,{ }^{* *} p<0.001$ negative control vectors.

\section{References}

1. McCampbell, K.K.; Springer, K.N.; Wingert, R.A. Analysis of nephron composition and function in the adult zebrafish kidney. J. Vis. Exp. 2014, 9, e51644. [CrossRef] [PubMed]

2. Vainio, S. How the developing mammalian kidney assembles its thousands of nephrons: Fgfs as stemness signals. Dev. Cell 2012, 22, 1125-1126. [CrossRef] [PubMed]

3. Saxen, L.; Sariola, H. Early organogenesis of the kidney. Pediatr. Nephrol. 1987, 1, 385-392. [CrossRef] [PubMed]

4. Nishita, M.; Qiao, S.; Miyamoto, M.; Okinaka, Y.; Yamada, M.; Hashimoto, R.; Iijima, K.; Otani, H.; Hartmann, C.; Nishinakamura, R.; et al. Role of Wnt5a-Ror2 signaling in morphogenesis of the metanephric mesenchyme during ureteric budding. Mol. Cell. Biol. 2014, 34, 3096-3105. [CrossRef] [PubMed]

5. Pope, J.C.T.; Brock, J.W., 3rd.; Adams, M.C.; Stephens, F.D.; Ichikawa, I. How they begin and how they end: Classic and new theories for the development and deterioration of congenital anomalies of the kidney and urinary tract, CAKUT. J. Am. Soc. Nephrol. 1999, 10, 2018-2028. [PubMed]

6. Tanigawa, S.; Sharma, N.; Hall, M.D.; Nishinakamura, R.; Perantoni, A.O. Preferential propagation of competent $\mathrm{Six}^{2+}$ nephronic progenitors by LIF/ROCKi treatment of the metanephric mesenchyme. Stem Cell Rep. 2015, 5, 435-447. [CrossRef] [PubMed]

7. Kobayashi, A.; Valerius, M.T.; Mugford, J.W.; Carroll, T.J.; Self, M.; Oliver, G.; McMahon, A.P. Six2 defines and regulates a multipotent self-renewing nephron progenitor population throughout mammalian kidney development. Cell Stem Cell 2008, 3, 169-181. [CrossRef] [PubMed]

8. lyu, Z.; Mao, Z.; Wang, H.; Fang, Y.; Chen, T.; Wan, Q.; Wang, M.; Wang, N.; Xiao, J.; Wei, H.; et al. MiR-181b targets Six 2 and inhibits the proliferation of metanephric mesenchymal cells in vitro. Biochem. Biophys. Res. Commun. 2013, 440, 495-501. [CrossRef] [PubMed]

9. Self, M.; Lagutin, O.V.; Bowling, B.; Hendrix, J.; Cai, Y.; Dressler, G.R.; Oliver, G. Six2 is required for suppression of nephrogenesis and progenitor renewal in the developing kidney. EMBO J. 2006, 25, 5214-5428. [CrossRef] [PubMed]

10. Vannier, C.; Mock, K.; Brabletz, T.; Driever, W. Zeb1 regulates E-cadherin and Epcam (epithelial cell adhesion molecule) expression to control cell behavior in early zebrafish development. J. Biol. Chem. 2013, 288, 18643-18659. [CrossRef] [PubMed] 
11. Eggers, J.C.; Martino, V.; Reinbold, R.; Schafer, S.D.; Kiesel, L.; Starzinski-Powitz, A.; Schuring, A.N.; Kemper, B.; Greve, B.; Gotte, M. microRNA miR-200b affects proliferation, invasiveness and stemness of endometriotic cells by targeting ZEB1, ZEB2 and KLF4. Reprod. Biomed. Online 2016, 32, 434-445. [CrossRef] [PubMed]

12. Tang, O.; Chen, X.M.; Shen, S.; Hahn, M.; Pollock, C.A. MiRNA-200b represses transforming growth factor-beta1-induced EMT and fibronectin expression in kidney proximal tubular cells. Am. J. Physiol. Ren. Physiol. 2013, 304, F1266-F1273. [CrossRef] [PubMed]

13. Gong, S.G.; Eulenberg, R.L. Palatal development in Twirler mice. Cleft Palate Craniofac. J. 2001, 38, $622-628$. [CrossRef]

14. Nishimura, G.; Manabe, I.; Tsushima, K.; Fujiu, K.; Oishi, Y.; Imai, Y.; Maemura, K.; Miyagishi, M.; Higashi, Y.; Kondoh, H.; et al. DeltaEF1 mediates TGF- $\beta$ signaling in vascular smooth muscle cell differentiation. Dev. Cell 2006, 11, 93-104. [CrossRef] [PubMed]

15. Liu, Y.; El-Naggar, S.; Darling, D.S.; Higashi, Y.; Dean, D.C. Zeb1 links epithelial-mesenchymal transition and cellular senescence. Development 2008, 135, 579-588. [CrossRef] [PubMed]

16. Senanayake, U.; Koller, K.; Pichler, M.; Leuschner, I.; Strohmaier, H.; Hadler, U.; Das, S.; Hoefler, G.; Guertl, B. The pluripotent renal stem cell regulator Six2 is activated in renal neoplasms and influences cellular proliferation and migration. Hum. Pathol. 2013, 44, 336-345. [CrossRef] [PubMed]

17. Zhou, P.; Chen, T.; Fang, Y.; Wang, H.; Li, M.; Ma, P.; He, L.; Li, Q.; Liu, T.; Yang, X.; et al. Down-regulated Six2 by knockdown of neurofibromin results in apoptosis of metanephric mesenchyme cells in vitro. Mol. Cell. Biochem. 2014, 390, 205-213. [CrossRef] [PubMed]

18. Reidy, K.J.; Rosenblum, N.D. Cell and molecular biology of kidney development. Semin. Nephrol. 2009, 29, 321-337. [CrossRef] [PubMed]

19. Multiple Sequence Aligment by CLUSTALW. Available online: http://www.genome.jp/tools/clustalw/ (accessed on 24 September 2015).

20. The Protein Database of National Center for Biotechnology Information. Available online: http://www.ncbi. nlm.nih.gov/protein. (accessed on 14 August 2015).

21. Xu, J.; Wong, E.Y.; Cheng, C.; Li, J.; Sharkar, M.T.; Xu, C.Y.; Chen, B.; Sun, J.; Jing, D.; Xu, P.X. Eya1 interacts with Six2 and Myc to regulate expansion of the nephron progenitor pool during nephrogenesis. Dev. Cell 2014, 31, 434-447. [CrossRef] [PubMed]

22. Yu, J.; Carroll, T.J.; McMahon, A.P. Sonic hedgehog regulates proliferation and differentiation of mesenchymal cells in the mouse metanephric kidney. Development 2002, 129, 5301-5312. [PubMed]

23. Takeyama, Y.; Sato, M.; Horio, M.; Hase, T.; Yoshida, K.; Yokoyama, T.; Nakashima, H.; Hashimoto, N.; Sekido, Y.; Gazdar, A.F.; et al. Knockdown of ZEB1, a master epithelial-to-mesenchymal transition (EMT) gene, suppresses anchorage-independent cell growth of lung cancer cells. Cancer Lett. 2010, 296, 216-224. [CrossRef] [PubMed]

24. Filios, S.R.; Xu, G.; Chen, J.; Hong, K.; Jing, G.; Shalev, A. MicroRNA-200 is induced by thioredoxin-interacting protein and regulates Zeb1 protein signaling and beta cell apoptosis. J. Biol. Chem. 2014, 289, 36275-36283. [CrossRef] [PubMed]

25. Xu, J.; Liu, H.; Park, J.S.; Lan, Y.; Jiang, R. Osr1 acts downstream of and interacts synergistically with Six2 to maintain nephron progenitor cells during kidney organogenesis. Development 2014, 141, 1442-1452. [CrossRef] [PubMed]

26. Crawford, E.D.; Wells, J.A. Caspase substrates and cellular remodeling. Annu. Rev. Biochem. 2011, 80, 1055-1087. [CrossRef] [PubMed]

27. Pop, C.; Salvesen, G.S. Human caspases: Activation, specificity, and regulation. J. Biol. Chem. 2009, 284, 21777-21781. [CrossRef] [PubMed]

28. Piatkov, K.I.; Brower, C.S.; Varshavsky, A. The N-end rule pathway counteracts cell death by destroying proapoptotic protein fragments. Proc. Natl. Acad. Sci. USA 2012, 109, E1839-E1847. [CrossRef] [PubMed]

29. Eldeeb, M.A.; Fahlman, R.P. The anti-apoptotic form of tyrosine kinase Lyn that is generated by proteolysis is degraded by the $\mathrm{N}$-end rule pathway. Oncotarget 2014, 5, 2714-2722. [CrossRef] [PubMed]

30. Liu, Y.; Sanchez-Tillo, E.; Lu, X.; Clem, B.; Telang, S.; Jenson, A.B.; Cuatrecasas, M.; Chesney, J.; Postigo, A.; Dean, D.C. Rb1 family mutation is sufficient for sarcoma initiation. Nat. Commun. 2013. [CrossRef] [PubMed]

31. Xu, B.; Lee, K.K.; Zhang, L.; Gerton, J.L. Stimulation of mTORC1 with L-leucine rescues defects associated with Roberts syndrome. PLoS Genet. 2013, 9, e1003857. [CrossRef] [PubMed] 
32. Bates, C.M. Kidney development: Regulatory molecules crucial to both mice and men. Mol. Genet. Metab. 2000, 71, 391-396. [CrossRef] [PubMed]

33. Couillard, M.; Trudel, M. C-myc as a modulator of renal stem/progenitor cell population. Dev. Dyn. 2009, 238, 405-414. [CrossRef] [PubMed]

34. Siemens, H.; Jackstadt, R.; Hunten, S.; Kaller, M.; Menssen, A.; Gotz, U.; Hermeking, H. miR-34 and SNAIL form a double-negative feedback loop to regulate epithelial-mesenchymal transitions. Cell Cycle 2011, 10, 4256-4271. [CrossRef] [PubMed]

35. The GenitoUrinary Development Molecular Anatomy Project Database. Available online: http://www. gudmap.org/gudmap/pages/mastertablebrowse.html (accessed on 10 September 2015).

36. The JASPAR Database. Available online: http://jaspar.genereg.net/cgi-bin/jaspar_db.pl. (accessed on 16 October 2015).

37. Sun, H.; Li, Q.W.; Lv, X.Y.; Ai, J.Z.; Yang, Q.T.; Duan, J.J.; Bian, G.H.; Xiao, Y.; Wang, Y.D.; Zhang, Z.; et al. MicroRNA-17 post-transcriptionally regulates polycystic kidney disease-2 gene and promotes cell proliferation. Mol. Biol. Rep. 2010, 37, 2951-2958. [CrossRef] [PubMed]

38. Balhana, R.; Stoker, N.G.; Sikder, M.H.; Chauviac, F.X.; Kendall, S.L. Rapid construction of mycobacterial mutagenesis vectors using ligation-independent cloning. J. Microbiol. Methods 2010, 83, 34-41. [CrossRef] [PubMed]

39. MISSION shRNA Clones for individual genes. Available online: http://www.Sigmaaldrich.com/chinamainland/zh/life-science/functional-genomics-and-rnai/shrna.html (accessed on 3 December 2015).

40. pLKO.1-ShRNA Construction. Available online: http://www.addgene.org/tools/protocols/plko/ (accessed on 12 December 2015).

41. Valerius, M.T.; Patterson, L.T.; Witte, D.P.; Potter, S.S. Microarray analysis of novel cell lines representing two stages of metanephric mesenchyme differentiation. Mech. Dev. 2002, 112, 219-232. [CrossRef]

42. McLaughlin, N.; Yao, X.; Li, Y.; Saifudeen, Z.; El-Dahr, S.S. Histone signature of metanephric mesenchyme cell lines. Epigenetics 2013, 8, 970-978. [CrossRef] [PubMed]

43. Tanigawa, S.; Wang, H.; Yang, Y.; Sharma, N.; Tarasova, N.; Ajima, R.; Yamaguchi, T.P.; Rodriguez, L.G.; Perantoni, A.O. Wnt4 induces nephronic tubules in metanephric mesenchyme by a non-canonical mechanism. Dev. Biol. 2011, 352, 58-69. [CrossRef] [PubMed]

44. Suwanjang, W.; Abramov, A.Y.; Charngkaew, K.; Govitrapong, P.; Chetsawang, B. Melatonin prevents cytosolic calcium overload, mitochondrial damage and cell death due to toxically high doses of dexamethasone-induced oxidative stress in human neuroblastoma SH-SY5Y cells. Neurochem. Int. 2016, 97, 34-41. [CrossRef] [PubMed]

45. Zhang, C.; Li, L.; Zhao, B.; Jiao, A.; Li, X.; Sun, N.; Zhang, J. Ghrelin protects against dexamethasone-induced INS-1 cell apoptosis via ERK and p38MAPK signaling. Int. J. Endocrinol. 2016. [CrossRef] [PubMed]

46. Guo, S.; Mao, L.; Ji, F.; Wang, S.; Xie, Y.; Fei, H.; Wang, X.D. Activating AMP-activated protein kinase by an alpha1 selective activator compound 13 attenuates dexamethasone-induced osteoblast cell death. Biochem. Biophys. Res. Commun. 2016, 471, 545-552. [CrossRef] [PubMed]

47. Brown, A.C.; Blank, U.; Adams, D.C.; Karolak, M.J.; Fetting, J.L.; Hill, B.L.; Oxburgh, L. Isolation and culture of cells from the nephrogenic zone of the embryonic mouse kidney. J. Vis. Exp. 2011. [CrossRef] [PubMed]

(C) 2016 by the authors; licensee MDPI, Basel, Switzerland. This article is an open access article distributed under the terms and conditions of the Creative Commons Attribution (CC-BY) license (http://creativecommons.org/licenses/by/4.0/). 